\title{
Groping in the Fog: Soaring Migrants Exhibit Wider Scatter in Flight Directions and Respond Differently to Wind Under Low Visibility Conditions
}

\author{
Paolo Becciu1,2,3*, Michele Panuccio ${ }^{2,4 \dagger}$, Giacomo Dell'Omo ${ }^{2}$ and Nir Sapir ${ }^{3}$ \\ ${ }^{1}$ Department of Ecology and Evolution, University of Lausanne, Lausanne, Switzerland, ${ }^{2}$ Ornis Italica, Rome, Italy, \\ ${ }^{3}$ Department of Evolutionary and Environmental Biology and Institute of Evolution, University of Haifa, Haifa, Israel, \\ ${ }^{4}$ MEDRAPTORS (Mediterranean Raptor Migration Network), Rome, Italy
}

\section{OPEN ACCESS}

Edited by:

Ann Valerie Hedrick,

University of California, Davis,

United States

Reviewed by:

Gil Bohrer,

The Ohio State University,

United States

Eileen Kirsch,

United States Geological Survey (USGS), United States

${ }^{*}$ Correspondence:

Paolo Becciu paolo.becciu@unil.ch; pbecciu89@gmail.com

${ }^{\dagger}$ Deceased

Specialty section:

This article was submitted to Behavioral and Evolutionary Ecology,

a section of the journal

Frontiers in Ecology and Evolution

Received: 21 July 2021 Accepted: 08 October 2021 Published: 29 October 2021

Citation:

Becciu P, Panuccio M, Dell'Omo G and Sapir N (2021) Groping in the Fog: Soaring Migrants

Exhibit Wider Scatter in Flight Directions and Respond Differently to Wind Under Low Visibility Conditions.

Front. Ecol. Evol. 9:745002. doi: 10.3389/fevo.2021.745002
Atmospheric conditions are known to affect flight propensity, behaviour during flight, and migration route in birds. Yet, the effects of fog have only rarely been studied although they could disrupt orientation and hamper flight. Fog could limit the visibility of migrating birds such that they might not be able to detect landmarks that guide them during their journey. Soaring migrants modulate their flight speed and direction in relation to the wind vector to optimise the cost of transport. Consequently, landmark-based orientation, as well as adjustments of flight speed and direction in relation to wind conditions, could be jeopardised when flying in fog. Using a radar system operated in a migration bottleneck (Strait of Messina, Italy), we studied the behaviour of soaring birds under variable wind and fog conditions over two consecutive springs (2016 and 2017), discovering that migrating birds exhibited a wider scatter of flight directions and responded differently to wind under fog conditions. Birds flying through fog deviated more from the mean migration direction and increased their speed with increasing crosswinds. In addition, airspeed and groundspeed increased in the direction of the crosswind, causing the individuals to drift laterally. Our findings represent the first quantitative empirical evidence of flight behaviour changes when birds migrate through fog and explain why low visibility conditions could risk their migration journey.

Keywords: bird migration, flight behaviour, Honey Buzzard, movement ecology, radar aeroecology, Strait of Messina, visual navigation

\section{INTRODUCTION}

Atmospheric conditions are known to affect flight propensity, behaviour during flight, and migration route in birds (Shannon et al., 2002; Shamoun-Baranes et al., 2010, 2017; Sherub et al., 2016; Becciu et al., 2019). Migration routes can be several thousand kilometres long, across many different ecosystems, landscapes, and climatic regions. Migratory birds are adapted to fly under different weather conditions, but in general, they prefer to fly in favourable atmospheric conditions. For instance, massive nocturnal migration in North America is triggered by mild temperatures (Van Doren and Horton, 2018), and flight over ecological barriers is facilitated by tailwinds or 
weak headwinds and is avoided under strong headwinds (Åkesson et al., 2016; Eisaguirre et al., 2018; Becciu et al., 2020; Santos et al., 2020; Nourani et al., 2021). Fog and low clouds may lower the visibility of landmarks and hamper orientation (Richardson, 1978, 1990; Chiaradia et al., 2007; Pastorino et al., 2017). Fog usually occurs in calm weather conditions (e.g., weak or no winds) near ground level, and its presence might be associated with otherwise good conditions for migration (Feng et al., 2006). Although birds may benefit from such weather, the low visibility associated with fog may cause disorientation and consequently avoidance of flight (Pastorino et al., 2017; Panuccio et al., 2019).

Bird flight behaviour and movement paths could consequently be affected by fog. For example, tracks of Sandhill Cranes (Antigone canadensis) recorded on a foggy day with a marine radar were more tortuous and circuitous than on days with good visibility (Kirsch et al., 2015). If the fog extends over a large area, birds could find themselves tens or even hundreds of kilometres away from their intended migratory routes and may become exhausted, as recorded for a flock of Turkey Vultures (Cathartes aura) flying over a fog-covered sea where the birds eventually alighted on a boat (Mote, 1969). Fog may even cause mass-mortality events of migrating birds (Newton, 2007) and may postpone their departure from stopover sites as they wait for better weather conditions. In some cases, birds may even undertake reverse migration when visibility is poor (Lack, 1960; Murton and Ridpath, 1962; Richardson, 1978; Pastorino et al., 2017). Indeed, fog was found to delay the arrival of birds at an offshore island in California (Pyle et al., 1993). These mostly anecdotical findings highlight the difficulty in studying how fog influences bird behaviour. Yet, more comprehensive studies regarding the effects of fog on wildlife can be undertaken in areas where fog prevails over long time periods. For example, Panuccio et al. (2019), who used radar to study soaring migrants in a migratory bottleneck in Southern Italy, documented a substantial decrease in migration intensity under foggy conditions, likely indicating avoidance behaviour.

Wind conditions can hamper or facilitate bird migration (Alerstam, 1979; Liechti, 2006; Gill et al., 2009; Deppe et al., 2015; Åkesson et al., 2016; Becciu et al., 2019). Specifically, due to the benefits of flying with favourable wind, tailwind assistance could lead to a decision to depart, resulting in a high migration traffic rate (Åkesson and Hedenström, 2000; Green et al., 2002; Nilsson et al., 2019). To reduce their flight cost and migration duration (Klaassen et al., 2011; Vansteelant et al., 2017; Becciu et al., 2018), flying migrants should continuously adjust their flight behaviour in response to changes in wind speed and direction as predicted by the optimal migration flight theory (Pennycuick, 1978; Alerstam, 1991; Bohrer et al., 2012). Consequently, their air- and groundspeed should change in a predictable manner (Becciu et al., 2018). Several studies have shown that both flapping and soaring birds reduce their airspeed under tailwinds and increase it under headwinds (Pennycuick, 1978; Alerstam, 1979; Liechti, 1995) and that the migrants' ground speed is also affected by tailwinds, headwind and crosswinds (Spaar and Bruderer, 1996, 1997; Safi et al., 2013; Vansteelant et al., 2015; Becciu et al., 2018). When gliding, soaring migrants reduce airspeed in tailwinds, which effectively increases distance covered (Spaar and Bruderer, 1996). This thereby reduces the chances of grounding and the need to switch to energetically costly flapping flight (Horvitz et al., 2014; Harel et al., 2016).

The aim of this study was to examine the effects of fog on orientation and response to wind in soaring migrants tracked by a marine radar over a migration bottleneck, The study was carried out at the Strait of Messina in Southern Italy, where Honey Buzzards (Pernis apivorous) comprise approximately 95\% of the tracked migrants (Becciu et al., 2018; Panuccio et al., 2018). We analysed the distribution of flight directions and the effects of wind conditions (speed and direction) on buzzard ground- and airspeed when they fly in fog versus clear conditions. We predicted a larger scatter of flight directions and different response to wind in fog, although to the best of our knowledge, no theory exists for flight behaviour in fog. In clear air, bird airspeed and flight direction are expected to change in predictable ways in relation to wind speed and direction to optimise the cost of transport (Pennycuick, 1978; Liechti et al., 1994). Whether birds will behave optimally in fog is not known and may depend on the information available to them under these conditions and no previous study has quantitatively estimated how flight may change under these conditions. If they rely on landmarks to calibrate their seasonal direction of flight and speed, and these landmarks are not visible in fog, the birds may risk flying off track and may not notice potential collision hazards simply due to lack of information required to assess their position and movement progress.

\section{MATERIALS AND METHODS}

\section{Study Area and Data Collection}

We collected the data during the spring migration of 2016 (24th March-7th May) and 2017 (22nd March-23rd May) near the edge of a flat highland frequently exposed to fog (Panuccio et al., 2019) in the Aspromonte Mountains, Calabria (38 $23^{\prime}$ $\mathrm{N}, 15^{\circ} 79^{\prime} \mathrm{E}-1030 \mathrm{~m}$ a.s.l.), about $7 \mathrm{~km}$ inland from the Strait of Messina in southern Italy (Figure 1). Fog and low clouds are generated in this area because humid air is trapped between the coast and the highland (Panuccio et al., 2019). We collected data using a $12 \mathrm{~kW}, \mathrm{X}$-band $(9.1 \mathrm{GHz})$ marine radar rotating at $38 \mathrm{RPM}$ with a $2.1-\mathrm{m}$ antenna that was set horizontally with a $22^{\circ}$ vertical beam. The radar covered a sector of $240^{\circ}$ (it was blanked toward the observers for the remaining angle) and its detection radius was about $2 \mathrm{~km}$, orienting toward the prevalent direction of the incoming migrants (a compass direction of $215^{\circ}$ ). Its horizontally rotating antenna enabled computing the direction and speed of the migrating birds based on the detection of their echoes and the reconstruction of their trajectories. Notably, we could not compute the altitude of the echoes. The radar was positioned in an area that is well known for its importance as migratory bottleneck for many species of birds and in particular for soaring raptors (Panuccio, 2011). Experienced birdwatchers carried out daily observations near the radar to characterise species composition and migration traffic rate (Schmidt et al., 2017). Radar measurements and direct 


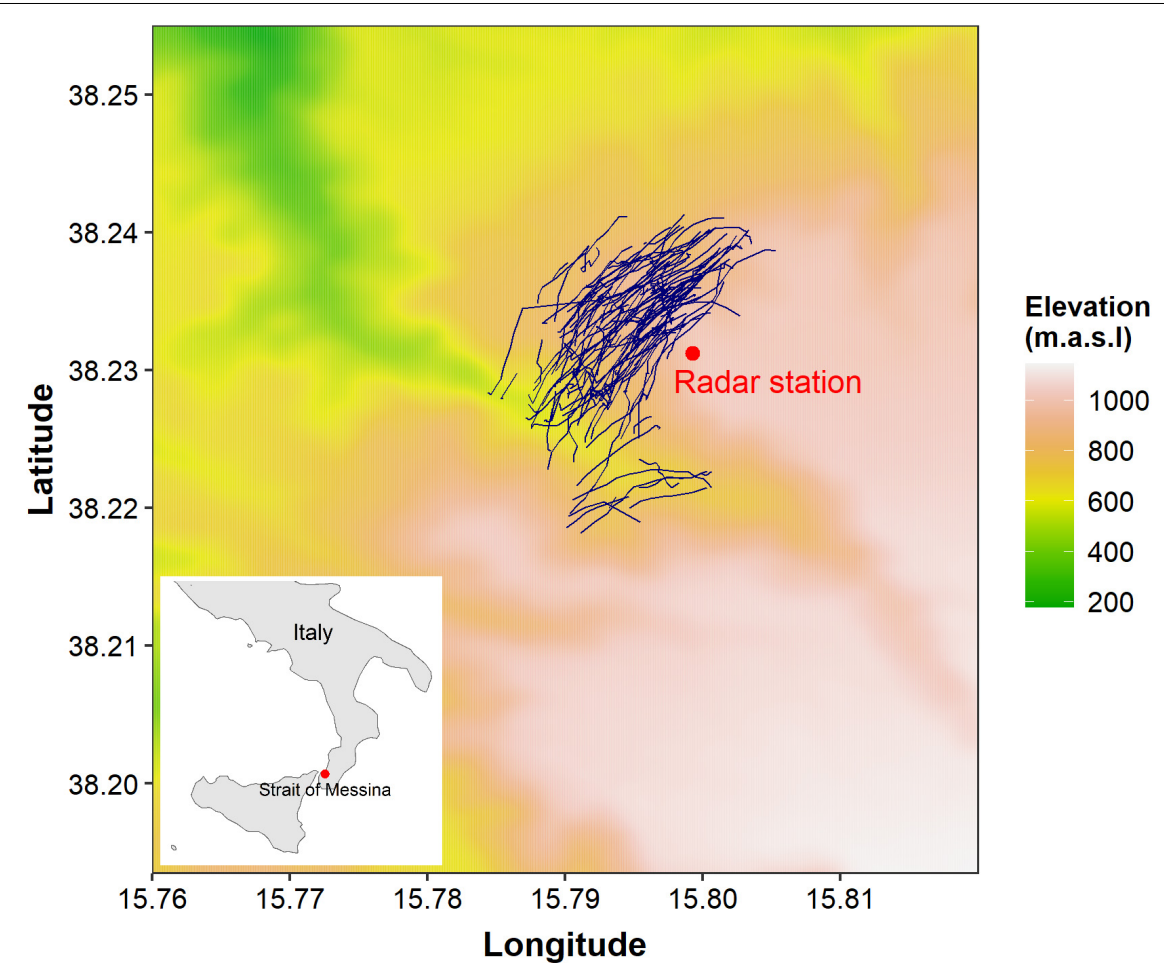

FIGURE 1 | Map of the study area showing the position of the radar and observers (red dot). Radar tracks of one day (20/04/2017) are depicted in dark blue. These tracks were recorded in a day without fog. Inset figure shows the study location in Southern Italy, in close proximity with the Strait of Messina.

observations of migrating birds took place daily during the study period, continuously between sunrise and sunset (UTC +1$)$, interrupted only occasionally by heavy precipitation.

Radar tracks were generated using Hypatia-trackRadar, a dedicated software that uses a supervised approach that minimises errors when estimating bird tracks from the radar echoes (Capotosti et al., 2019). The programme translates the echoes to a metric coordinate system and based on time and spatial position of the echoes, it automatically calculates multiple flight parameters, such as groundspeed, track length, and duration. In addition, the software allowed us to associate the echoes with the species observed by the birdwatchers. We filtered out tracks less than $100 \mathrm{~m}$ long and with a groundspeed of less than $5 \mathrm{~m} / \mathrm{s}$. Data regarding processed tracks are available in the DRYAD repository (doi: 10.5061/dryad.8gtht76q8).

\section{Weather Data}

The presence of fog and low clouds was visually assessed by the radar operators and the birdwatchers. It was recorded (presence/absence) by assigning a presence value for each hour in which visibility was lower than $0.3 \mathrm{~km}$ for at least 15 consecutive min, disregarding isolated passing clouds for details on the method, (see Panuccio et al., 2019). Hourly U (eastward) and V (northward) components of the wind (10 $\mathrm{m}$ above ground) were downloaded from the ERA5 dataset of the European Centre for Medium-Range Weather Forecast (ECMWF) repository. ERA5 provides hourly estimates of a large number of atmospheric variables on a $30 \mathrm{~km}$ grid. We could not assess the exact height of the flying birds, hence we assumed that wind speed at $10 \mathrm{~m}$ above the ground level was correlated to the wind speed at the height of birds' flight (Becciu et al., 2020; Solano et al., 2021). We used the wind components to calculate tailwind and crosswind speeds (hereafter TW and CW, respectively) relative to the mean seasonal (springtime) migration direction of the birds $\left(\theta_{b}\right)$, which is considered as their overall heading (Sapir et al., 2011; Becciu et al., 2018):

$$
\begin{aligned}
& T W=v_{w} \cdot \cos \left(\theta_{w}-\theta_{b}\right), \\
& C W=v_{w} \cdot \cos \left(\left(\theta_{w}-\frac{\pi}{2}\right)-\theta_{b}\right),
\end{aligned}
$$

where $\theta_{w}$ is the mean wind direction and $v_{w}$ is the wind speed.

We noted that fog occurred only when the wind was blowing toward the sector that is between 90.92 and $179.22^{\circ}$. Thus, we filtered out all bird tracks recorded when the wind blew in directions beyond/outside this angular sector. In addition, we retained only tracks for which wind speeds were lower than $7.2 \mathrm{~m} / \mathrm{s}$, since foggy conditions were almost always above this wind speed (Supplementary Figure 1).

\section{Movement Parameters}

To test if bird movement changed under different wind and fog conditions, we calculated several variables derived from their radar tracks, including:

1. Groundspeed: we calculated it as the simple ratio between distance covered and time passed between two consecutive 
points $\left(v_{g}\right)$. We calculated the groundspeed component relative to the mean direction of migration $\left(\theta_{b}\right)$ as a projected segment toward that specific direction $\left(v_{g M}\right)$ :

$$
v_{g M}=v_{g} \cdot \cos \left(\theta_{i}-\theta_{b}\right),
$$

where $\theta_{i}$ is the mean direction of the individual track.

2. Airspeed: we calculated it like (Safi et al., 2013), using the wind components crosswind $(C W)$ and tailwind (TW) which were calculated in relation to the mean direction of migration $\left(\theta_{b}\right)$ :

$$
\begin{aligned}
v_{a} & =\sqrt{\left(v_{g}-T W\right)^{2}+(C W)^{2}}, \\
v_{a M} & =v_{a} \cdot \cos \left(\theta_{i}-\theta_{b}\right),
\end{aligned}
$$

where $v_{a}$ is the airspeed in relation to $T W$ and $C W$ experienced by the buzzards, and $v_{a M}$ is the $v_{a}$ component relative to the mean direction of migration $\left(\theta_{b}\right)$.

3. Sideways speed: we calculated the bird's lateral speed relative to $\theta_{b}$ with the following formula:

$$
v_{s M}=v_{g} \cdot \sin \left(\theta_{i}-\theta_{b}\right) .
$$

All angles are expressed in radians.

We calculated the mean migration direction $\left(\theta_{b}\right)$ as the circular mean of all tracks collected from buzzards that passed through the radar's detection area in fair weather only. Furthermore, we used hourly means of bird movement parameters to match the temporal resolution of the wind measurements. In addition, we filtered out tracks that deviated more than $100^{\circ}$ from the $\theta_{b}$ (either to the left or to the right of this angle) to exclude the movement of local and non-migrating birds.

\section{Statistical Analysis}

We used Watson's $U^{2}$ test (Watson's Two-Sample Test of Homogeneity) to compare the track directions under fog to those without fog (Landler et al., 2021). We modelled hourly means of groundspeed $\left(v_{g M}\right)$, airspeed $\left(v_{a M}\right)$, and sideways speed $\left(v_{s M}\right)$ as functions of the tailwind and the crosswind components of the wind (continuous variables) and fog presence (binomial). Wind data is at the same temporal resolution (hourly values) to avoid eventual pseudo-replication (having many tracks recorded in a certain hour that are matched with a single wind parameter value). We used linear mixed effect models (LMMs), with ordinal date as an intercept random effect. We found the optimal structure of the fixed components of the model and ran the models with different combinations of the fixed effect terms (tailwind, crosswind and fog presence) in the global model. We used the log-transformed count of tracks per hour as weights in the model. To evaluate model fit, we used the Akaike Information Criterion (AIC; Akaike, 1973), by applying the function dredge from the MuMIn package in R (Barton, 2019; $\mathrm{R}$ Core Team, 2020). Following inspection of model residuals and considering the dispersion of the data using the DHARMa package (Hartig, 2019), we chose LMM as the most appropriate (Zuur et al., 2009). Statistical analyses were performed in R 4.1.0
(R Core Team, 2020) using packages $\operatorname{glmmTMB}$ (Brooks et al., 2017) and circular (Agostinelli and Lund, 2017). Plots and a table of the models were produced using the packages sjPlot (Lüdecke, 2021) and ggplot2 (Wickham, 2016).

\section{RESULTS}

We recorded a total of 60,552 radar tracks; of these, 2,885 (4.8\%) were recorded during foggy conditions (Figure 2 and also see Supplementary Figure 2 for the number of tracks per day in fog and fair-weather conditions). After filtering out tracks that did not meet the wind speed and direction criteria (as explained in see section "Materials and Methods"), we retained 28,553 tracks. The mean flight direction of birds differed significantly between birds that flew under clear skies (96\% of the tracks) and fog (4\% of the tracks) conditions (Watson's $U^{2}$ test: test-statistic $=2.99$, $p<0.001$ ), with a mean direction of $57.3^{\circ}$ under clear skies and $80.7^{\circ}$ under foggy conditions (Figure 2 ).

Mean hourly values for groundspeed, airspeed and sideways speed were computed for a total of $270 \mathrm{~h}$ of radar operation. The selected statistical models with groundspeed and sideways speed relative to the mean migration direction as dependent variables did not include tailwind and its interaction with fog condition, while the model selected for explaining bird airspeed retained tailwind but not its interaction with fog presence (Table 1).

Soaring migrants flying in foggy and non-foggy conditions over the study area had, in general, similar groundspeeds, but they differed in their response to crosswind speed (Figure 3). Increased crosswind speed under clear skies induced a decrease of groundspeed, while groundspeed increased with crosswind speed under foggy conditions (Table 1 and Figure 3). It should be noted that due to the filtering of the tracks, the crosswind component contains only positive values, indicating a wind blowing toward the bird's right-hand side (Figures 3-5).

Under clear skies and foggy conditions, birds reduced their airspeed with increasing tailwind speed, as expected (Table 1 and Figure 4A). With increasing crosswinds, buzzards flying under clear skies decreased their airspeed while those flying under fog increased their airspeed (Figure 4B).

Sideways speed differed between buzzards flying in fog versus clear air (Table 1 and Figure 5A). In foggy conditions, sideways speed increased toward the right side of the migration goal (positive values), in the inland direction. Birds travelling under clear skies had a negative sideways speed, meaning that they moved more toward the coast (Table 1 and Figure 5A). The general response of the birds to crosswind was slightly different; under clear skies they tended to direct their flight toward inland areas under weak crosswinds and toward the coast with increasing crosswind speed (Table 1 and Figure 5B). When crosswinds were weak, birds flew toward the general direction of the presumed migration goal (dashed line in Figure 5), but under the same crosswind conditions, bird that flew in the fog overcompensated for wind drift by travelling toward the coast. With increasing crosswind speed, the birds eventually compensated for the lateral drift by flying toward the presumed migration goal (Figure 5B). For birds travelling in foggy condition, the sideways 

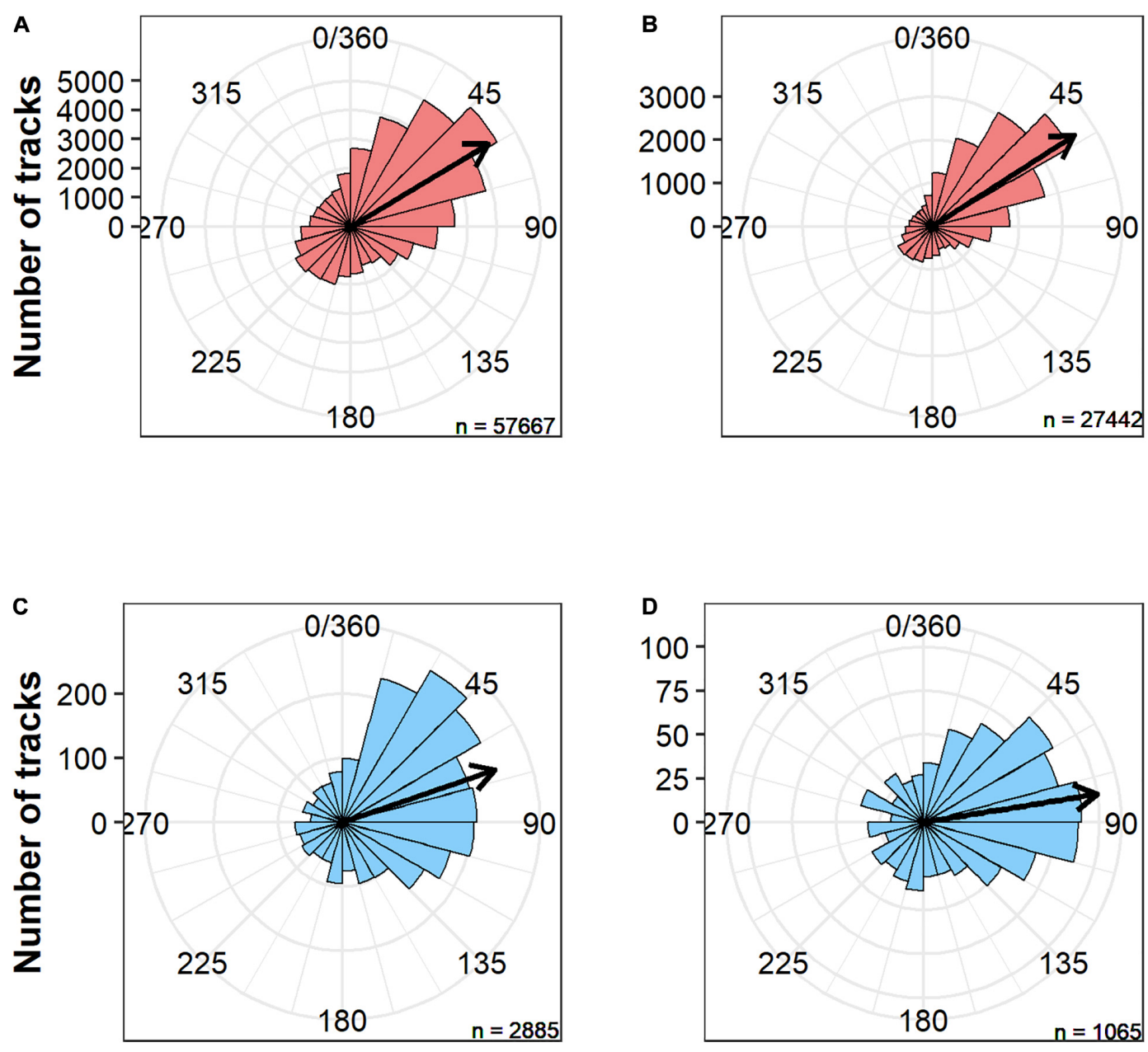

Bird directions

\section{Bird directions}

FIGURE 2 | Circular distribution of (A) all tracks recorded under clear skies, (B) tracks recorded under clear skies in selected wind conditions that match those recorded during fog events, (C) tracks recorded under fog conditions, and (D) tracks recorded under fog conditions in selected wind conditions. Black arrows are mean circular directions.

TABLE 1 | The selected linear mixed models reporting the effects of wind and fog on bird average hourly speeds.

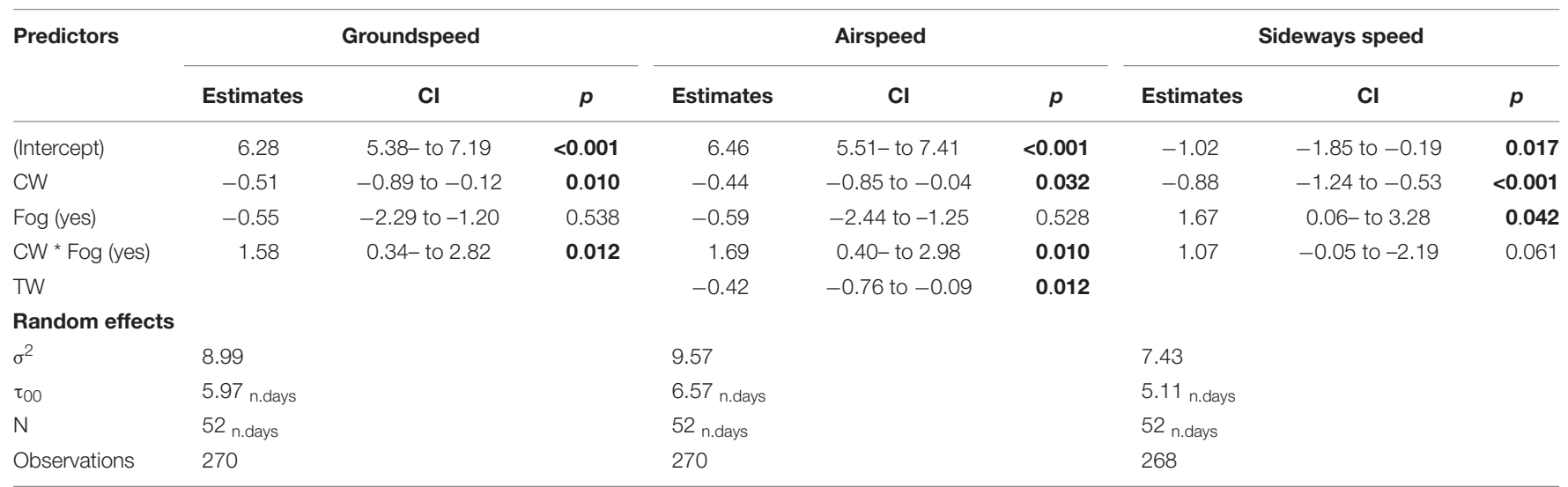

Continuous predictors are scaled (z-transformed). Significant $p$-values are in bold. 


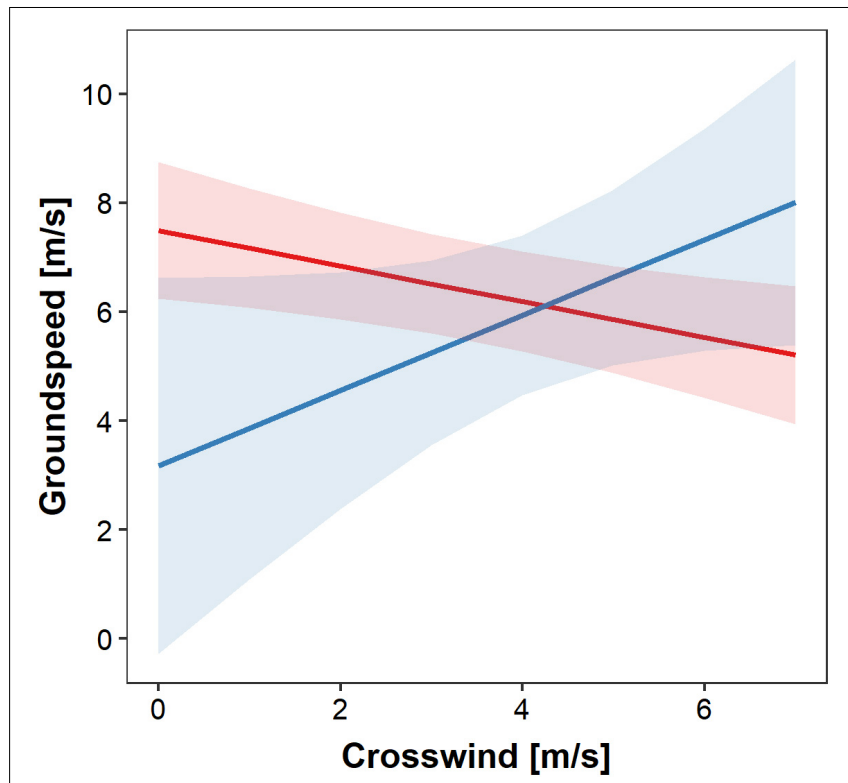

FIGURE 3 | The effects of crosswind on groundspeed of Honey Buzzards migrating through fog (blue) and under clear skies (red). Regression slopes and $95 \%$ C.I. of the groundspeed in relation to crosswind in foggy conditions (blue) and clear weather (red). Crosswinds all have positive values since they only represent wind blowing from the left to the right side of the average migration direction.

speed varied too much to establish a clear response, but their response clearly differed from that of birds flying in clear weather.

\section{DISCUSSION}

Our findings demonstrate that fog affects bird orientation and the modulation of flight speed in relation to wind during migration. We found that the birds' flight directions were more scattered under foggy conditions and that the mean migration direction changed when fog was present. As described in an earlier study, soaring migrants' densities are drastically ( 95\%) reduced in fog (Panuccio et al., 2019), and the present study uncovers the reasons for this avoidance, suggesting that bird orientation can be disrupted and the cost of transport could be elevated such that the migration trip may become more risky and costly. For example, birds try to bypass fog by displacing themselves in an unpredictable manner or to distant places (Mote, 1969; Feng et al., 2006), or worse, they might hit a natural or artificial obstacle obscured by fog. To avoid this risk, birds flying in fog often land and wait until the fog clears to resume their migration (Lack, 1960; Pastorino et al., 2017). Fog may make spotting key landmarks necessary for maintaining a certain route direction difficult, consequently influencing bird behaviour and movement.

We found that soaring birds flying under both clear skies and foggy conditions modulated their ground and air speed in relation to tail- and headwind as predicted by optimal migration flight theory (Pennycuick, 1978; Alerstam, 1991), whereas bird response to the crosswind component of the wind was different under foggy conditions. The increase in airspeed, and consequently groundspeed, with increasing crosswinds could help birds to get out of areas covered by fog. Yet, such behaviour may expose birds to higher risk of collision with structures obscured by the fog, such as buildings, communication towers, power lines and wind turbines (Lack, 1960; Drewitt and Langston, 2006; Aschwanden et al., 2018). Furthermore, changes in bird sideways speed in foggy conditions could result in more scattered tracks that diverge from the intended migration goal, as can be expected under limited visibility conditions in general (Lack, 1960; Mote, 1969; Pastorino et al., 2017) and observed in this study. Soaring migrants that faced increasing crosswinds (from sea to land, as in Figure 5B) under clear skies tended to fly toward land, but during foggy events, sideways speed was very variable and this can be reflected by the scattered mean track directions around the migration goal vector (Figures 2C,D). It seems that the birds were ranging between under-compensating for lateral drift to over-compensating as the crosswind component increased in clear weather and this response differed under foggy conditions. These findings are the first illustration of how fog influences the flight properties of soaring migrants.

The lack of data on the spatial and temporal properties of fog in meteorological databases limits broad-scale analysis of the effects of fog on migrating animals; thus, only a handful of small-scale studies have been conducted so far to study these phenomena (Kirsch et al., 2015; Panuccio et al., 2019). Some of these studies investigated orientation behaviour under fog, including a study that found that fog prevented Little Penguins (Eudyptula minor) from crossing land to reach their nests walking, probably affecting their orientation and delaying their nest attendance (Chiaradia et al., 2007). Other studies, mostly anecdotal, suggested that fog also affected migrating dragonflies (Feng et al., 2006), migrating storks (Pastorino et al., 2017), and vultures (Mote, 1969). In nocturnal species, fog amplifies the glow of artificial lights and influences the orientation of birds (Lack, 1960; Guilford et al., 2019) and insects (Becciu et al., 2019). As already proposed by Panuccio et al. (2019), we believe that the consequences of flying in fog must be considered when estimating bird collision risks in human-made structures in areas where fog is common.

The scatter of flight directions under foggy conditions that we documented could be genuine but might also be explained by our inability to properly define the spatial extent and the intensity of the fog around the radar station. It is possible that some birds were outside the fog when tracked (or perhaps above it), and some experienced different visibility of landmarks when flying in the fog due to variations in fog intensity. We occasionally saw some of the buzzards during the fog events near the radar site, and noticed that the birds dramatically decreased their flight elevation and flew very close to the ground, perhaps to see landmarks. The possibility to measure altitude along with changes in the birds' horizontal position would be of great use to explain flight behaviour in low visibility conditions in future studies. We note that radar technology provides a valuable means for collecting data and quantifying behavioural changes in birds flying in fog, as direct observations of birds in these conditions are nearly impossible (Becciu et al., 2019). 

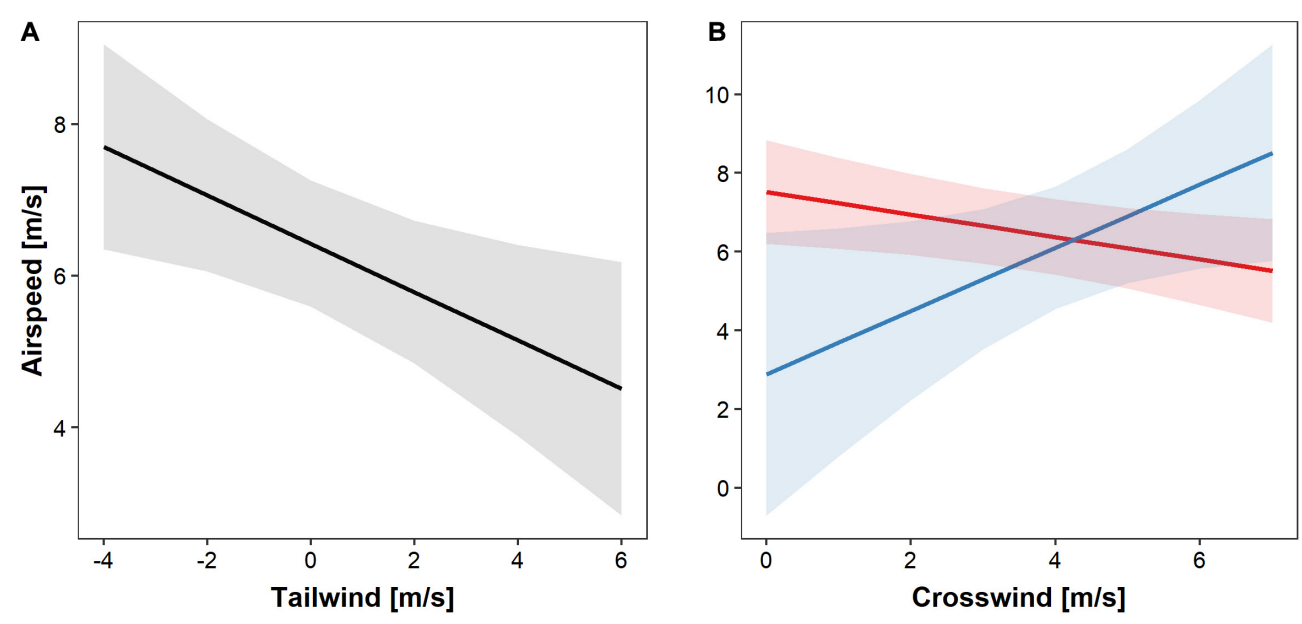

FIGURE 4 | The effects of crosswind and tailwind speed on airspeed of Honey Buzzards migrating through fog or under clear skies. (A) Regression slope and 95\% C.I. of the airspeed in relation to tailwind. (B) Regression slopes and 95\% C.I. of the airspeed in relation to crosswind in foggy conditions (blue) and clear weather (red). Crosswinds all have positive values since they only represent wind blowing from the left to the right side of the average migration direction.
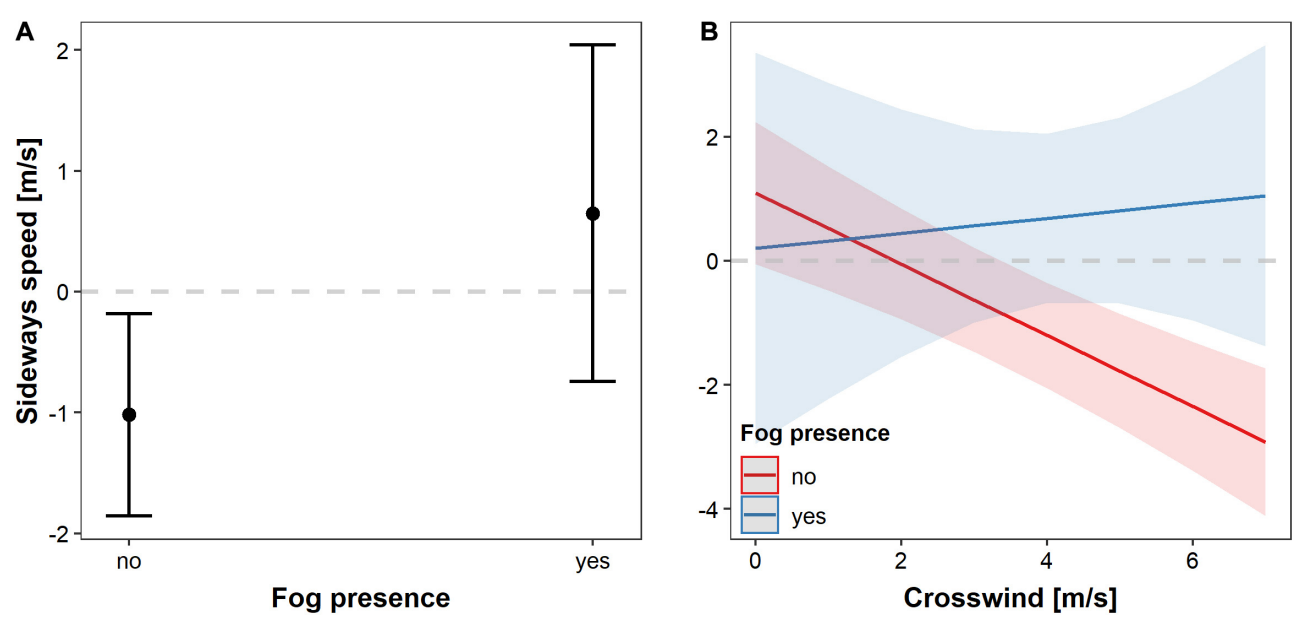

FIGURE 5 | The effects of crosswind on bird sideways speed. (A) Sideways speed mean and 95\% C.I. (whiskers) for tracks in foggy and clear weather conditions. (B) Regression slopes and 95\% C.I. of the sideways speed in relation to the crosswind component through fog or under clear skies. The dashed line marks the $y$-intercept at $0 \mathrm{~m} / \mathrm{s}$ sideways speed, representing the presumable direction of flight toward the migration goal. Crosswinds have only positive values since they only represent the wind blowing from the left to the right side of the average migration direction.

Our findings show that birds flying in fog do not adjust their flight behaviour as well as they do in good visibility conditions, with possible consequences that could lower bird survival. Finally, our findings represent the first empirical evidence of the variation of flight behaviour under foggy conditions in migratory birds, highlighting how birds may cope with the risks of flying in low visibility conditions.

\section{DATA AVAILABILITY STATEMENT}

The raw data supporting the conclusion of this article will be made available by the authors in the DRYAD repository (doi: 10.5061/dryad.8gtht76q8), without undue reservation.

\section{AUTHOR CONTRIBUTIONS}

$\mathrm{PB}, \mathrm{MP}$, and NS contributed to conception and design of the study. GD and MP collected the data. MP organised the dataset. $\mathrm{PB}$ performed the statistical analysis and wrote the first draft of the manuscript. All authors contributed to manuscript revision, read, and approved the submitted version.

\section{FUNDING}

This work was partially funded by Terna Rete Italia S.p.A., COST-European Cooperation in Science and Technology through the Action ES1305 European Network for the Radar 
Surveillance of Animal Movement (ENRAM), and University of Haifa, Haifa, Israel.

\section{ACKNOWLEDGMENTS}

Data collection was supported by Terna Rete Italia S.p.A. We thank Ornis italica which supported our fieldwork. We thank all the people involved in the field as radar operators and as birdwatchers. MP was partially funded by COST-European Cooperation in Science and Technology through the Action

\section{REFERENCES}

Agostinelli, C., and Lund, U. (2017). R package "circular": Circular Statistics (version 0.4-93).

Akaike, H. (1973). "Information theory and an extension of the maximum likelihood principle," in 2nd International Symposium on Information Theory Akadémiai Kiadó, Budapest, 267-281.

Åkesson, S., and Hedenström, A. (2000). Wind selectivity of migratory flight departures in birds. Behav. Ecol. Sociobiol. 47, 140-144.

Åkesson, S., Bianco, G., and Hedenstrom, A. (2016). Negotiating an ecological barrier: crossing the Sahara in relation to winds by common swifts. Philos. Trans. R. Soc, B Biol. Sci. 371:20150393. doi: 10.1098/rstb.2015.0393

Alerstam, T. (1979). Wind as selective agent in bird migration. Ornis Scand. 10, 76-93. doi: $10.2307 / 3676347$

Alerstam, T. (1991). Bird flight and optimal migration. Trends Ecol. Evol. 6, 210-215. doi: 10.1016/0169-5347(91)90024-R

Aschwanden, J., Stark, H., Peter, D., Steuri, T., Schmid, B., and Liechti, F. (2018). Bird collisions at wind turbines in a mountainous area related to bird movement intensities measured by radar. Biol. Conserv. 220, 228-236. doi: 10.1016/j. biocon.2018.01.005

Barton, K. (2019). MuMIn: Multi-Model Inference. Version 1.43.6. R Package Version 1.42. 1, 1-75.

Becciu, P., Menz, M. H. M., Aurbach, A., Cabrera-Cruz, S. A., Wainwright, C. E., Scacco, M., et al. (2019). Environmental effects on flying migrants revealed by radar. Ecography 42, 942-955. doi: 10.1111/ecog.03995

Becciu, P., Panuccio, M., Catoni, C., Dell'Omo, G., and Sapir, N. (2018). Contrasting aspects of tailwinds and asymmetrical response to crosswinds in soaring migrants. Behav. Ecol. Sociobiol. 72:28. doi: 10.1007/s00265-018-2 447-0

Becciu, P., Rotics, S., Horvitz, N., Kaatz, M., Fiedler, W., Zurell, D., et al. (2020). Causes and consequences of facultative sea crossing in a soaring migrant. Funct. Ecol. 34, 840-852. doi: 10.1111/1365-2435.13539

Bohrer, G., Brandes, D., Mandel, J. T., Bildstein, K. L., Miller, T. A., Lanzone, M., et al. (2012). Estimating updraft velocity components over large spatial scales: contrasting migration strategies of golden eagles and turkey vultures. Ecol. Lett. 15, 96-103. doi: 10.1111/j.1461-0248.2011.01713.x

Brooks, M. E., Kristensen, K., van Benthem, K. J., Magnusson, A., Berg, C. W., Nielsen, A., et al. (2017). glmmTMB balances speed and flexibility among packages for zero-inflated generalized linear mixed modeling. $R$ J. 9, 378-400. doi: $10.32614 /$ rj-2017-066

Capotosti, S., Scacco, M., Nelli, L., Dell, G., and Panuccio, M. (2019). HypatiatrackRadar: a software for animal tracking using marine surveillance radars. Ecol. Informat. 53:100972. doi: 10.1016/j.ecoinf.2019.100972

Chiaradia, A., McBride, J., Murray, T., and Dann, P. (2007). Effect of fog on the arrival time of little penguins Eudyptula minor: a clue for visual orientation? J. Ornithol. 148, 229-233. doi: 10.1007/s10336-007-0125-5

Deppe, J. L., Ward, M. P., Bolus, R. T., Diehl, R. H., Celis-Murillo, A., Zenzal, T. J., et al. (2015). Fat, weather, and date affect migratory songbirds' departure decisions, routes, and time it takes to cross the Gulf of Mexico. Proc. Natl. Acad. Sci. U.S.A. 112, E6331-E6338. doi: 10.1073/pnas.150338 1112

Drewitt, A. L., and Langston, R. H. W. (2006). Assessing the impacts of wind farms on birds. Ibis 148, 29-42. doi: 10.1111/j.1474-919X.2006.00516.x
ES1305 European Network for the Radar Surveillance of Animal Movement (ENRAM). We would also like to thank G. Bohrer and E. Kirsch for their useful comments that substantially improved our work, and S. Turjeman for the English revisions.

\section{SUPPLEMENTARY MATERIAL}

The Supplementary Material for this article can be found online at: https://www.frontiersin.org/articles/10.3389/fevo.2021. 745002/full\#supplementary-material

Eisaguirre, J. M., Booms, T. L., Barger, C. P., McIntyre, C. L., Lewis, S. B., and Breed, G. A. (2018). Local meteorological conditions reroute a migration. Proc. R. Soc. B Biol. Sci. 285:20181779. doi: 10.1098/rspb.2018.1779

Feng, H. Q., Wu, K. M., Ni, Y. X., Cheng, D. F., and Guo, Y. Y. (2006). Nocturnal migration of dragonflies over the Bohai Sea in northern China. Ecol. Entomol. 31, 511-520. doi: 10.1111/j.1365-2311.2006.00813.x

Gill, R. E., Tibbitts, T. L., Douglas, D. C., Handel, C. M., Mulcahy, D. M., Gottschalck, J. C., et al. (2009). Extreme endurance flights by landbirds crossing the Pacific Ocean: ecological corridor rather than barrier? Proc. R. Soc. B Biol. Sci. 276, 447-457. doi: 10.1098/rspb.2008.1142

Green, M., Alerstam, T., Clausen, P., Drent, R., and Ebbinge, B. S. (2002). Darkbellied brent geese Branta bernicla bernicla, as recorded by satellite telemetry, do not minimize flight distance during spring migration. Ibis 144, 106-121. doi: 10.1046/j.0019-1019.2001.00017.x

Guilford, T., Padget, O., Bond, S., and Syposz, M. (2019). Light pollution causes object collisions during local nocturnal manoeuvring flight by adult Manx Shearwaters Puffinus puffinus. Seabird 31, 48-55.

Harel, R., Duriez, O., Spiegel, O., Fluhr, J., Horvitz, N., Getz, W. M., et al. (2016). Decision-making by a soaring bird: time, energy and risk considerations at different spatio-temporal scales. Philos. Trans. R. Soc. B Biol. Sci. 371:20150397. doi: 10.1098/rstb.2015.0397

Hartig, F. (2019). DHARMa: Residual Diagnostics for Hierarchical (multilevel/mixed) Regression Models.

Horvitz, N., Sapir, N., Liechti, F., Avissar, R., Mahrer, I., and Nathan, R. (2014). The gliding speed of migrating birds: slow and safe or fast and risky? Ecol. Lett. 17, 670-679. doi: 10.1111/ele.12268

Kirsch, E. M., Wellik, M. J., Suarez, M., Diehl, R. H., Lutes, J., Woyczik, W., et al. (2015). Observation of Sandhill Cranes' (Grus canadensis) flight behavior in heavy fog. Wilson J. Ornithol. 127, 281-288. doi: 10.1676/wils-127-02-281288.1

Klaassen, R. H. G., Hake, M., Strandberg, R., and Alerstam, T. (2011). Geographical and temporal flexibility in the response to crosswinds by migrating raptors. Proc. R. Soc. B Biol. Sci. 278, 1339-1346. doi: 10.1098/rspb.2010.2106

Lack, D. (1960). The influence of weather on passerine migration. A review. Auk 77, 171-209.

Landler, L., Ruxton, G. D., and Malkemper, E. P. (2021). Comparing two circular distributions: advice for effective implementation of statistical procedures in biology. bioRxiv [Preprint]. doi: 10.1101/2021.03.25.436932

Liechti, F. (1995). Modelling optimal heading and airspeed of migrating birds in relation to energy expenditure and wind influence. J. Avian Biol. 26, 330-336. doi: $10.2307 / 3677049$

Liechti, F. (2006). Birds: blowin' by the wind? J. Ornithol. 147, 202-211. doi: 10.1007/s10336-006-0061-9

Liechti, F., Hedenström, A., and Alerstam, T. (1994). Effects of sidewinds on optimal flight speed of birds. J. Theor. Biol. 170, 219-225. doi: 10.1006/jtbi.1994. 1181

Lüdecke, D. (2021). R Package 'sjPlot': Data Visualization for Statistics in Social Science (version 2.8.8).

Mote, W. R. (1969). Turkey vultures land on vessel in fog. Auk 86, 766-767.

Murton, R. K., and Ridpath, M. G. (1962). The autumn movements of the Woodpigeon. Bird Study 9, 7-41. doi: 10.1080/00063656209476010

Newton, I. (2007). Weather-related mass-mortality events in migrants. Ibis 149, 453-467. 
Nilsson, C., Dokter, A. M., Verlinden, L., Shamoun-Baranes, J., Schmid, B., Desmet, P., et al. (2019). Revealing patterns of nocturnal migration using the European weather radar network. Ecography 42, 876-886. doi: 10.1111/ecog.0 4003

Nourani, E., Bohrer, G., Becciu, P., Bierregaard, R. O., Duriez, O., Figuerola, J., et al. (2021). The interplay of wind and uplift facilitates over-water flight in facultative soaring birds. Proc. R. Soc. B Biol. Sci. 288:20211603. doi: 10.1098/ rspb.2021.1603

Panuccio, M. (2011). Wind effects on visible raptor migration in spring at the strait of messina. Southern Italy. J. Raptor Res. 45, 88-92. doi: 10.3356/jrr-10-16.1

Panuccio, M., Agostini, N., Bogliani, G., and Dell'Omo, G. (2018). Migrating raptor counts: the need for sharing objectives and field protocols, and the benefits of using radar. Bird Study 65, S77-S84. doi: 10.1080/00063657.2018.150 6423

Panuccio, M., Dell'Omo, G., Bogliani, G., Catoni, C., and Sapir, N. (2019). Migrating birds avoid flying through fog and low clouds. Int. J. Biometeorol. 63, 231-239. doi: 10.1007/s00484-018-01656-z

Pastorino, A., Roman, J. R., Agostini, N., Dell'omo, G., and Panuccio, M. (2017). Fog and rain lead migrating white storks Ciconia ciconia to perform reverse migration and to land. Avocetta 41, 5-12.

Pennycuick, C. J. (1978). Fifteen testable predictions about bird flight. Oikos 30, 165-176. doi: $10.2307 / 3543476$

Pyle, P., Nur, N., Henderson, R. P., and DeSante, D. F. (1993). The effects of weather and lunar cycle on nocturnal migration of landbirds at southeast farallon Island. California. Condor 95, 343-361.

R Core Team (2020). R: A Language and Environment for Statistical Computing. Vienna: R Core Team.

Richardson, W. J. (1978). Timing and amount of bird migration in relation to weather: a review. Oikos 30, 224-272. doi: 10.2307/3543482

Richardson, W. J. (1990). “Timing of bird migration in relation to weather: updated review," in Bird Migration, ed. E. Gwinner (Berlin: Springer Berlin Heidelberg), 78-101. doi: 10.1007/978-3-642-74542-3_6

Safi, K., Kranstauber, B., Weinzierl, R., Griffin, L., Rees, E. C., Cabot, D., et al. (2013). Flying with the wind: scale dependency of speed and direction measurements in modelling wind support in avian flight. Mov. Ecol. 1, 1-13. doi: 10.1186/2051-3933-1-4

Santos, C. D., Silva, J. P., Muñoz, A. R., Onrubia, A., and Wikelski, M. (2020). The gateway to Africa: what determines sea crossing performance of a migratory soaring bird at the Strait of Gibraltar? J. Anim. Ecol. 89, 1317-1328. doi: 10. 1111/1365-2656.13201

Sapir, N., Wikelski, M., Avissar, R., and Nathan, R. (2011). Timing and flight mode of departure in migrating European bee-eaters in relation to multi-scale meteorological processes. Behav. Ecol. Sociobiol. 65, 1353-1365. doi: 10.1007/ s00265-011-1146-x

Schmidt, M., Aschwanden, J., Liechti, F., Wichmann, G., and Nemeth, E. (2017). Comparison of visual bird migration counts with radar estimates. Ibis 159, 491-497. doi: 10.1111/ibi.12473

Shamoun-Baranes, J., Bouten, W., and Van Loon, E. E. (2010). Integrating meteorology into research on migration. Integr. Comp. Biol. 50, 280-292. doi: $10.1093 /$ icb/icq011
Shamoun-Baranes, J., Liechti, F., and Vansteelant, W. M. G. (2017). Atmospheric conditions create freeways, detours and tailbacks for migrating birds. J. Comp. Physiol. A 203, 509-529. doi: 10.1007/s00359-017-1181-9

Shannon, H. D., Young, G. S., Yates, M. A., Fuller, M. R., and Seegar, W. S. (2002). American white pelican soaring flight times and altitudes relative to changes in thermal depth and intensity. Condor 104, 679-683.

Sherub, S., Bohrer, G., Wikelski, M., and Weinzierl, R. (2016). Behavioural adaptations to flight into thin air. Biol. Lett. 12, 4-8. doi: 10.1098/rsbl.2016.0432

Solano, J. C., Montaño, T., Maldonado-Correa, J., Ordóñez, A., and Pesantez, M. (2021). Correlation between the wind speed and the elevation to evaluate the wind potential in the southern region of Ecuador. Energy Rep. 7, 259-268. doi: 10.1016/j.egyr.2021.06.044

Spaar, R., and Bruderer, B. (1996). Soaring migration of steppe eagles aquila nipalensis in southern israel: flight behaviour under various wind and thermal conditions. J. Avian Biol. 27, 289-301.

Spaar, R., and Bruderer, B. (1997). Optimal flight behavior of soaring migrants: a case study of migrating steppe buzzards, buteo buteo vulpinus. Behav. Ecol. 8, 288-297. doi: 10.1093/beheco/8.3.288

Van Doren, B. M., and Horton, K. G. (2018). A continental system for forecasting bird migration. Science 361, 1115-1118. doi: 10.1126/science.aat7526

Vansteelant, W. M. G., Bouten, W., Klaassen, R. H. G., Koks, B. J., Schlaich, A. E., van Diermen, J., et al. (2015). Regional and seasonal flight speeds of soaring migrants and the role of weather conditions at hourly and daily scales. J. Avian Biol. 46, 25-39. doi: 10.1111/jav.00457

Vansteelant, W. M. G., Shamoun-Baranes, J., van Manen, W., van Diermen, J., and Bouten, W. (2017). Seasonal detours by soaring migrants shaped by wind regimes along the East Atlantic Flyway. J. Anim. Ecol. 86, 179-191. doi: 10.1111/ $1365-2656.12593$

Wickham, H. (2016). ggplot2: Elegant Graphics for Data Analysis, 2nd Edn. Berlin: Springer Nature, doi: 10.1111/j.1467-985x.2010.00676_9.x

Zuur, A. F., Ieno, E. N., Walker, N., Saveliev, A. A., and Smith, G. M. (2009). Mixed Effects Models and Extension in Ecology With R. Berlin: Springer Science \& Business Media.

Conflict of Interest: The authors declare that the research was conducted in the absence of any commercial or financial relationships that could be construed as a potential conflict of interest.

Publisher's Note: All claims expressed in this article are solely those of the authors and do not necessarily represent those of their affiliated organizations, or those of the publisher, the editors and the reviewers. Any product that may be evaluated in this article, or claim that may be made by its manufacturer, is not guaranteed or endorsed by the publisher.

Copyright (c) 2021 Becciu, Panuccio, Dell'Omo and Sapir. This is an open-access article distributed under the terms of the Creative Commons Attribution License (CC BY). The use, distribution or reproduction in other forums is permitted, provided the original author(s) and the copyright owner(s) are credited and that the original publication in this journal is cited, in accordance with accepted academic practice. No use, distribution or reproduction is permitted which does not comply with these terms. 